\title{
PRODUÇÕES CURRICULARES E EDUCAÇÃO INFANTIL - APOSTAS OU GARANTIAS?
}

\author{
CURRICULUM PRODUCTIONS AND EARLY CHILDHOOD EDUCATION - BETS OR \\ GUARANTEES?
}

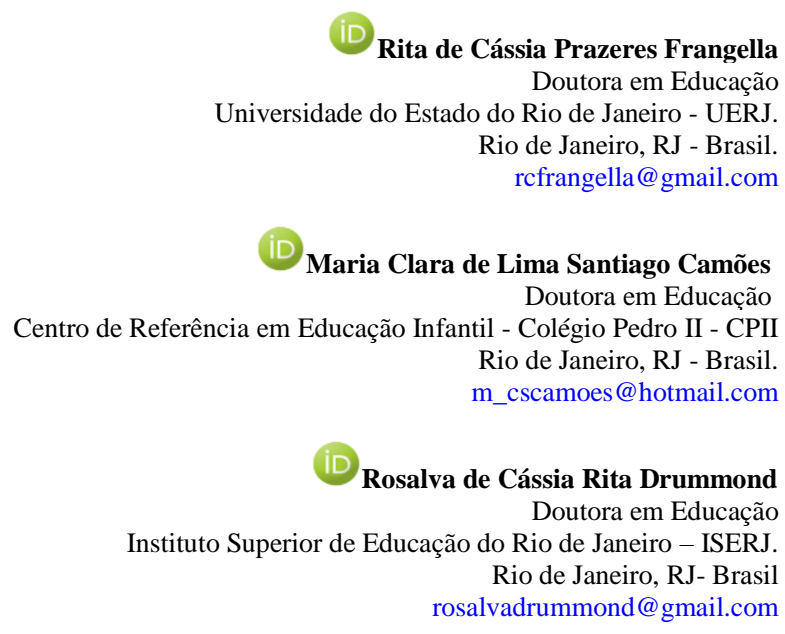

Resumo: O artigo tematiza a relação entre currículo e Educação Infantil, a partir da retomada de políticas curriculares desenvolvidas nas últimas décadas, problematizando a Base Nacional Comum Curricular (BNCC) para Educação Infantil, promulgada em 2017 e que, tal como versa o documento, insere a Educação Infantil no contexto da Educação Básica e sendo assim, como se propõe para as outras etapas, ainda que atentando para as suas especificidades, também traz a indicação de aprendizagens consideradas essenciais, numa lógica que reduz educação ao ensino. Tomamos como mote de problematização a questão do direito à aprendizagem e desenvolvimento, questão que é apresentada como justificativa mesmo da BNCC, inquirindo sobre as articulações discursivas que vão alinhando direito à aprendizagem à igualdade e que, como discutimos, desliza para um entendimento do comum como único, num caráter homogeneizante que impele ao silenciamento da diferença. Desenvolvemos a argumentação a partir de aportes pós-estruturais que se assentam na compreensão da política como produção discursiva, luta pela significação em jogos de linguagem sempre instáveis e inconclusos, em que os fechamentos são provisórios pois o trabalho da significação é fluxo ininterrupto. Discutimos a concepção de currículo que norteia as pesquisas que temos desenvolvido, tomando-o como uma enunciação cultural, que se constitui em meio a negociações com e na diferença. Assim, pomos em debate os sentidos postos quanto ao direito à aprendizagem e a definição prévia das experiências, advogando em favor de outros sentidos, na defesa da experiência como acontecimento alteritário.

Palavras-chave: BNCC; direito à aprendizagem; discurso; educação infantile; políticas curriculares

Abstract: The paper analyzes the relationship between curriculum and early childhood education, based on the resumption of curricular policies developed in the last decades, problematizing the National Curricular Common Base (BNCC) for Early Childhood Education, enacted in 2017 and which, as the document covers, Early Childhood Education in the context of Basic Education and thus, as it is proposed for the other stages, although attending to their specifics, also brings the indication of learning considered essential, in a logic that reduces education to teaching. The issue of the right to learning and development is taken as a motto of problematization, an issue that is presented as justification even for the BNCC, inquiring about the discursive articulations that are aligning the right to learning with equality that as we have discussed, slips into an understanding of the common as unique, in a homogenizing character that impels the silencing of difference. We develop the argument from post-structural contributions that are based on the understanding of politics as discursive production, struggle for meaning in ever unstable and inconclusive language games, in which closures are provisional because the work of signification is uninterrupted flow. We discuss the conception of curriculum that drives the research we have developed, taking it as a cultural enunciation, which is in the midst of negotiations with and in difference. Thus, we put in debate the meanings placed on the right to learning and the prior definition of experiences, advocating in favor of other senses, in the defense of experience as an alteritary event.

Keywords: BNCC; right to learn; discourse; early childhood education; curricular policies.

Para citar - (ABNT NBR 6023:2018)

FRANGELlA, Rita de Cássia Prazeres; CAMÕES, Maria Clara de Lima Santiago; DRUMMOND, Rosalva de Cássia Rita. Produções curriculares e educação infantil - apostas ou garantias?. Eccos - Revista Científica, São Paulo, n. 59, p. 1-19, e13657, out./dez. 2021.

Disponível em: https://doi.org/10.5585/eccos.n59.13657. 
Temos acompanhado, especialmente a partir de 1999 - momento da elaboração dos Referenciais Curriculares Nacionais para a Educação Infantil - RCNEI (Brasil, 1999) pelo Ministério da Educação (MEC) - uma articulação mais expressiva de demandas curriculares para a Educação Infantil. Isso se dá num contexto de mudanças que foram promovidas/promoveram a própria discussão acerca da concepção da educação infantil, que se desdobraram, entre outras ações, na promulgação da Lei de Diretrizes e Bases Nacionais $\mathrm{n}^{\circ}$ 9394/96, que passou então a reconhecer a Educação Infantil como primeira etapa da Educação Básica, dispondo em seu Artigo 29 (alterado pela Lei n 12.796, de 2013) que “A educação infantil, primeira etapa da educação básica, tem como finalidade o desenvolvimento integral da criança até seis anos de idade, em seus aspectos físico, psicológico, intelectual e social, complementando a ação da família e da comunidade." (BRASIL, 1996).

Mais de 20 anos se passaram e tem sido crescente atenção à Educação Infantil no que tange às políticas educacionais: ações referentes ao financiamento, a ampliação da oferta de vagas, formação dos educadores, Diretrizes Curriculares, qualidade de atendimento, avaliação... O estudo que apresentamos põe em destaque questões acerca da produção curricular na Educação Infantil, campo que tem se alargado em sua produção e que movimenta as discussões sobre a própria significação da Educação Infantil, num contexto de disputa de perspectivas que se acirram com a promulgação da Base Nacional Comum Curricular - BNCC (Brasil, 2017) que, se por um lado, discute e inclui a Educação Infantil no contexto da Educação Básica, numa articulação que não põe a Infância à parte das políticas educacionais propostas, por outro, insere a produção curricular para infância num contexto de recrudescimento de uma lógica de centralização curricular que vem sendo denunciada e problematizada de forma contundente por entidades e pesquisadores do campo.

A proposta de BNCC busca se apresentar como precisa e clara, considerando essas adjetivações positivas. No entanto, ao fazê-lo, evidencia seu compromisso com uma compreensão tecnicista e ultrapassada de currículo, bem como uma concepção equivocada da linguagem. As pesquisas no campo do Currículo, em sua imensa maioria, consideram indesejáveis e impossíveis essas características. A polissemia inerente à linguagem, que é conotativa e não denotativa, interdita a compreensão clara e precisa de textos. Os significados das palavras não são intrínsecos a elas, são estabelecidos por meio de processos de negociação de sentidos, o que significa que não há precisão ou clareza, desejável ou possível. As escolhas sobre como usar uma palavra não são de natureza individual e nos confrontamos com decisões sobre como interpretar as escolhas feitas. A ênfase na qualificação de que o que é proposto na BNCC prima pela clareza, precisão e explicitação das aprendizagens que se espera que todos façam, cria um contraponto com o que se visa a superar e indica um caminho único, sem ramificações/atalhos/outros caminhos e oportunidades também possíveis. (ABdC, 2017. Disponível em: https://www.abdcurriculo.com.br/documentos. Acesso em mar/2019). 
Uma das justificativas que suportam o desenrolar dos movimentos que culminaram na produção BNCC se assenta sobre a questão do avanço na qualidade da educação de forma que essa se dê com equidade e justiça social. Num intricado jogo de articulações, isso se alinha a defesa de garantia de direitos de aprendizagem. Quando chamamos atenção para os deslocamentos discursivos e articulações produzidas que permitem que determinadas significações emerjam o fazemos assentadas nas perspectivas que orientam as pesquisas por nós desenvolvidas - a compreensão do currículo em diálogo com as contribuições dos estudos pós-estruturalistas caminha para a assunção do currículo numa perspectiva discursiva. Os processos de significação dependem da negociação de significados, a ambivalência discursiva que torna a política possível. Considerando a falta de estrutura aprioristicamente constituída que fundamente os fenômenos sociais e o excesso de sentidos, a produção de novos sentidos pelos jogos de linguagem será incessante, dando aos processos de significação o caráter de provisório. Assim, entendemos a produção de políticas curriculares como produções políticodiscursivas que se dão numa luta pela significação.

Objetivamos observar a produtividade dessa negociação/articulação que, no jogo da significação, articula a ideia de igualdade à homogeneidade. A BNCC sustenta o conceito de comum a todos como garantia dos direitos de aprendizagem essenciais. Que direitos?

Encontramos na leitura de Derrida (2012) aporte para discutir o sentido de direito que perpassa a BNCC. Para o autor (2010), a constituição de direito sempre carregará consigo algum tipo de exclusão, seja de algo ou alguém, uma vez que o direito se faz na tentativa de homogeneização, como norma. Assim, faz-se necessário arguir os sentidos do argumento justificador da proposição de um comum nacional através da afirmação de um direito, pela defesa de um sentido de justiça como algo generalizado e homogêneo.

A noção de direito à educação, vista como direito universal e, de forma rasa, entendido como direito à escolaridade, incide na defesa pelo direito de aprendizagem. Há uma limitação que deriva da substituição automática do direito à educação pela ideia de escolaridade. É importante ressaltar que como McCowan (2011) alerta,

[...] é difícil determinar o ponto em que a educação deixa de ser um direito e passa a ser apenas um bem. Com esta colocação, não estamos sugerindo que rejeitamos a noção do direito à educação, mas que reconhecemos que esse direito tem uma aplicação muito mais ampla do que normalmente se pensa. (p.13)

Contudo, observamos como essas transmutações - do direito à educação ao direito de aprendizagem, de referenciais curriculares à normativas - vão significando não só o currículo, mas também a própria educação infantil. Problematizamos a tensão da institucionalização da 
infância através de políticas que, na tentativa de garantir o direito à educação, produzem sentidos que parecem reduzir os sentidos de infância e educação infantil. Assim, questionamos: currículo para educação infantil - aposta ou garantia?

\section{Itinerários curriculares no campo da infância}

O Brasil tem perseguido a expansão do acesso e a melhoria no atendimento a Educação Infantil, reconhecidamente como espaço para o desenvolvimento da primeira infância, este caminho, entretanto, traz aspectos que dizem não só do direito de acesso, mas criam demandas à produção curricular.

Em 2009, ao aprovar a ampliação da faixa de escolaridade obrigatória de 6 a 14 anos para 4 a 17 anos (EC n 59/2009) a oferta de vagas na pré-escola para todas as crianças de 4 a 5 anos passou a se configurar como dever do Estado, estabelecendo o ano de 2016 como limite para o cumprimento do dispositivo legal de obrigatoriedade da matrícula das crianças de 4 e 5 anos de idade na pré-escola. Sobre essa obrigatoriedade, Didonet (2010) aponta para o risco de cindir novamente a Educação Infantil em duas partes - a pré-escola, obrigatória, ressaltando sua importância educacional e a creche, não obrigatória, que perde importância educacionalmente. A indagação do autor nos remete a um atendimento a infância que teve origem a partir da demanda da classe operária por um lugar de acolhimento às crianças pequenas durante a jornada de trabalho das famílias e para promover o desenvolvimento saudável das crianças das classes mais abastadas, numa época em que a preocupação ganhou contornos como uma espécie de prescrição curricular para a educação infantil, com ênfase na complementaridade aos cuidados da família no que se refere aos aspectos de higiene, alimentação, segurança, descanso, entre outros. As tensões entre o cuidar e o educar, marcados por sentidos que configuram o trabalho pedagógico na Educação Infantil, posto em discussão. Paralelo a esta discussão, não foi difícil vincular a obrigatoriedade de matrícula na Pré-escola à formalização de uma proposta curricular marcada pela lógica da preparação para o Ensino Fundamental. Nesta lógica da obrigatoriedade, evidenciou-se o questionamento dos professores sobre a necessidade de preparação para a alfabetização.

Como direito, parece que a estreita relação entre o nome do que dizem por "direito" limita-se ao "que se precisa aprender". Retomam assim as questões que dizem respeito à aprendizagem e ao ensino, reduzindo o currículo à perspectiva instrumental do que é passível de ser ensinado, possível de se tornar comum, na lógica do que se pode ser avaliado. 
Quando retomamos aspectos da história das políticas educacionais para Educação Infantil, não podemos negar avanços no que tange ao atendimento das crianças brasileiras. $\mathrm{O}$ entendimento da criança como sujeito de direitos (Constituição Federal de 1988 e Estatuto da Criança e do Adolescente, 1990) e o reconhecimento da EI como primeira etapa da Educação Básica (LDB 9394/96), são, como já mencionados, conquistas importantes, com essas questões contudo, a discussão em torno da questão curricular ganhou foco no atendimento à primeira infância e demanda atenção. Neste movimento estiveram envolvidos diferentes setores de representação social e das políticas públicas, além dos debates oriundos da academia e dos organismos internacionais, resultando na organização de documentos como Referencial Curricular Nacional para a Educação Infantil (Brasil, 1999) e as Diretrizes Curriculares Nacionais para a Educação Infantil (Brasil, 2009) esta última sob a forma de lei. No que tange a discussão acerca da questão curricular, os conteúdos ganham destaque nos Referenciais Curriculares, apontando para um conhecimento que se organiza de forma intencional, a partir de bases pré-estruturadas. Trata-se de um alinhamento que assinala para uma presunção que define à priori os conhecimentos a serem apreendidos. Nos Referenciais Curriculares Nacionais para a Educação Infantil evidencia-se como se dão as diferentes aprendizagens:

Por meio de sucessivas reorganizações do conhecimento. [...] É importante marcar
que não há aprendizagem sem conteúdos [...] Pesquisas e produções teóricas
realizadas, principalmente durante a última década, apontam a importância das
aprendizagens específicas para os processos de desenvolvimento e socialização do ser
humano, ressignificando o papel dos conteúdos nos processos de aprendizagem. [...]
Os conteúdos abrangem, para além de fatos, conceitos e princípios, também os
conhecimentos relacionados a procedimentos, atitudes, valores e normas como
objetos de aprendizagem. A explicitação de conteúdos de naturezas diversas aponta
para a necessidade de se trabalhar de forma intencional e integrada com conteúdos
que, na maioria das vezes, não são tratados de forma explícita e consciente. Esta
abordagem é didática e visa a destacar a importância de se dar um tratamento
apropriado aos diferentes conteúdos, instrumentalizando o planejamento do professor
para que possa contemplar as seguintes categorias: os conteúdos conceituais que
dizem respeito ao conhecimento de conceitos, fatos e princípios; os conteúdos
procedimentais referem-se ao "saber fazer" e os conteúdos atitudinais estão
associados a valores, atitudes e normas (BRASIL, 1999, p. 49).

As Diretrizes Curriculares Nacionais para a Educação Infantil (DCNEIs) destacavam a necessidade de estruturar e organizar ações educativas com qualidade, articulada com a valorização do papel dos professores que atuam junto às crianças de 0 a 5 anos. Na Revisão das Diretrizes Curriculares Nacionais para a Educação Infantil, em parecer homologado publicado no D.O.U. de 9/12/2009, o currículo é definido como: 


\begin{abstract}
Um conjunto de práticas que buscam articular as experiências e os saberes das crianças com os conhecimentos que fazem parte do patrimônio cultural, artístico, científico e tecnológico. Tais práticas são efetivadas por meio de relações sociais que as crianças desde bem pequenas estabelecem com os professores e as outras crianças, e afetam a construção de suas identidades. Intencionalmente planejadas e permanentemente avaliadas, as práticas que estruturam o cotidiano das instituições de Educação Infantil devem considerar a integralidade e indivisibilidade das dimensões expressivo-motora, afetiva, cognitiva, linguística, ética, estética e sociocultural das crianças, apontar as experiências de aprendizagem que se espera promover junto às crianças e efetivar-se por meio de modalidades que assegurem as metas educacionais de seu projeto pedagógico (BRASIL, 2009, p.6).
\end{abstract}

O que queremos dizer com isso é que, se por um lado avançamos no que diz respeito a formalização de uma política para a Educação Infantil, na mesma direção temos caminhado ante binarismos bastante difundidos no campo. Evidenciam-se produtos ou processos? Conhecimentos pré-definidos ou experiências? Que apostas ou garantias estão postas em jogo: aprendizagens cognitivas ou desenvolvimento integral? Sob qual ponto de vista?

No esforço do reconhecimento da Educação Infantil como espaço indissociável de educação e cuidado, como instância potente de experiências de aprendizagens das crianças e campo profissional dos professores e professoras instituiu-se processos que agregam não só um ganho, do ponto de vista do reconhecimento do trabalho pedagógico, mas de forma ambivalente, geram sentidos que tendem ao engessamento das propostas pedagógicas para as infâncias.

$\mathrm{O}$ argumento do direito como articulador de diferentes interesses parece autorizar o arranjo proposto na produção dessas políticas e ao aceitá-lo, entretanto, coloca-se sob questão a justiça. Acompanhamos a interrogação de Derrida (2010) ao perguntar:

\footnotetext{
Como conciliar $o$ ato de justiça, que deve sempre concernir a singularidade, indivíduos, grupos, existências insubstituíveis, o outro ou eu como outro, numa situação única, com a regra, a norma, o valor ou o imperativo de justiça, que têm necessariamente uma forma geral, mesmo que essa generalidade prescreva uma aplicação que é, cada vez, singular? (p. 31)
}

Nesse jogo de significação do que venha ser o direito à educação e suas garantias pelo direito de aprendizagem, o currículo da educação infantil tem sido frequentemente questionado, emerge como demanda que mobiliza e movimenta a produção no campo.

\title{
BNCC: $\underline{\text { um }}$ currículo para a Educação Infantil?
}

As discussões acerca da Base Nacional Curricular Comum (BNCC) criou espaço para que muitas questões sobre a Educação Infantil fossem retomados, a própria trajetória das três versões sinaliza o contexto de disputa de sentidos instaurado nesse processo de produção da 
BNCC, sendo esta uma proposição que intenciona equalizar conhecimentos, conteúdos e culturas, partindo de um discurso de efetivação de objetivos conteudinais a serem alcançados pelos professores e alunos.

O Ministério da Educação (MEC) reativou, a partir do Programa Currículo em Movimento de 2009, a defesa de uma base comum para o currículo. A BNCC foi apresentada pelo MEC em setembro de 2015 como um documento de caráter normativo, uma política do Estado brasileiro, onde são propostos conteúdos, competências e habilidades a serem ensinados em cada etapa da Educação escolar (Educação Infantil, Ensino Fundamental - anos iniciais e anos finais e Ensino Médio). A argumentação da necessidade de uma base encontra forte sustentação na previsão das legislações vigentes (Constituição de 1988, LDB e PNE) e nesse sentido à tarefa de construção de uma Base foi dado um caráter quase imperativo:

A Base Nacional Comum Curricular (BNCC) estabelece os direitos, os conhecimentos, as competências e os objetivos de aprendizagem para todas as crianças e adolescentes brasileiros desde a Educação Infantil até o Ensino Médio. Ela está prevista na Constituição Brasileira, na Lei de Diretrizes e Bases da Educação (LDB) e no Plano Nacional de Educação (PNE). É um documento normativo, uma política do Estado brasileiro. (Disponível em http://basenacionalcomum.mec.gov.br/a-base, acesso em 14/04/2017).

A BNCC, ao prever os conteúdos a serem ensinado nas escolas, apresenta um sentido de política curricular enquanto documento a ser seguido e evidencia a produção de uma política que intenciona centralizar os conhecimentos e culturas. É, pois, inscrita nessa compreensão que a Base se evidencia como representação de uma particularidade que agora se pretende universalizar e controlar (pelo menos aparentemente) as disputas políticas que marcaram sua construção.

A articulação política em torno da BNCC se assenta, como sugerem Lopes e Cunha (2017) na crença da educação como totalidade, na leitura estrutural da sociedade como totalidade fechada e diante desta totalidade, a educação, por meio da BNCC, "desempenha a tarefa de salvação, de sutura da falta de qualidade" (p. 3).

O debate sobre o currículo na Educação Infantil tem gerado controvérsias acerca de sua concepção. Os destaques feitos a partir das significações que se depreendem dos RCNEIs, das DCNEIs e da BNCC indicam esse movimento: o currículo ora é visto como conteúdo (RCNEIs), ora como articulação de experiências, com foco na ação mediadora da instituição de Educação infantil e articuladora das experiências e saberes das crianças (DCNEIs) ou evidencia um retorno a perspectiva conteudista de equalização e distribuição do conhecimento (BNCC). O currículo diante destas múltiplas significações se apresenta como disputa política, naturalmente instável, e como define Lopes (2018): 


\begin{abstract}
Um projeto educativo só se coaduna com a mudança social se o julgamento sobre "o que somos de melhor" estiver sempre aberto a contestação. Pressupor normas que estabeleçam de uma vez por todas qual o melhor projeto educativo, qual o melhor conhecimento, as melhores atividades na escola, os valores válidos, o melhor currículo, o melhor porvir pode facilmente se inserir na lógica autoritária de decidir no lugar do outro. (p. 147)
\end{abstract}

Partimos, então, do pressuposto de que a criação de uma proposta pedagógica para a Educação Infantil em um contexto de transformações legais e disputas políticas nesse campo de conhecimento ocorre no tensionamento e negociação entre as diferentes experiências.

Com base em Derrida (2010) evidenciamos a experiência da aporia como uma travessia, de modo que o real não se localiza neste ou naquele lugar, na saída ou na chegada, ele se dispõe na travessia. Um espaço-tempo transitório, um caminho onde perturba-se a ideia de fronteira, um para além da experiência que aponta para uma certa originalidade ou radicalidade da própria experiência, o que implica a possibilidade de pensar experiência como acontecimento. Em termos desconstrutivos a noção de experiência evidencia a impossibilidade de acesso a realidade das coisas, aproximando-se de uma ideia de não-experiência ou experiência impossível, pois a coisa mesma sempre escapa. A infância é vista como uma experiência transcendental do espaço, do tempo e da linguagem. A idéia de experiência em Derrida concebida a partir de uma perspectiva de fluidez nos permite articular tal perspectiva àquelas que tem ancorado a concepção de currículo que defendemos: como produção discursiva, contingencial e provisória.

A defesa da construção de um currículo para a infância que se faz na experiência nos faz questionar a proposição curricular vigente na BNCC, que se diz estruturada por campos de experiência. A organização do currículo por campos de experiência está na pauta de debate de diferentes pesquisadores que intencionam construir uma proposta assentadas nas especificidades da educação infantil. Visto deste modo, a defesa de um currículo como experiência, como estaríamos na contramão de uma Base que se erige assim, por campos de experiência? As pesquisas que temos desenvolvido (Camões, 2019; Drummond, 2019) problematiza os sentidos de experiência que tem sido mobilizados e como ele se evidencia na BNCC, que colide com a perspectiva de experiência que defendemos: a experiência como acontecimento, produção negociada na com diferença, uma experiência que se move na singularidade e não na preditividade observada no documento, a partir da sua definição apriorística.

O texto da BNCC para Educação Infantil evidencia, logo no início, o processo histórico de constituição de uma educação para a infância nas últimas décadas no Brasil dando destaque 
a sua integração ao conjunto da Educação Básica e o rompimento com a perspectiva de preparação. Tal qual propõe as Diretrizes Curriculares Nacionais para a Educação Infantil (2009) afirma as interações e as brincadeiras como eixos estruturantes. O esquema exemplificado (Figura 1) descreve o modo pelo qual o documento organiza-se. Estão definidos seis direitos de aprendizagem (conviver, brincar, participar, explorar, comunicar e conhecer-se) aliados aos seguintes campos de experiência: $\mathrm{O}$ eu, o outro e o nós; Corpo, gestos e movimentos; Traços, sons, cores e formas; Escuta, fala, pensamento e imaginação, Espaços, tempos, quantidades, relações e transformações.

Figura 1 - Direitos de aprendizagem citados na BNCC

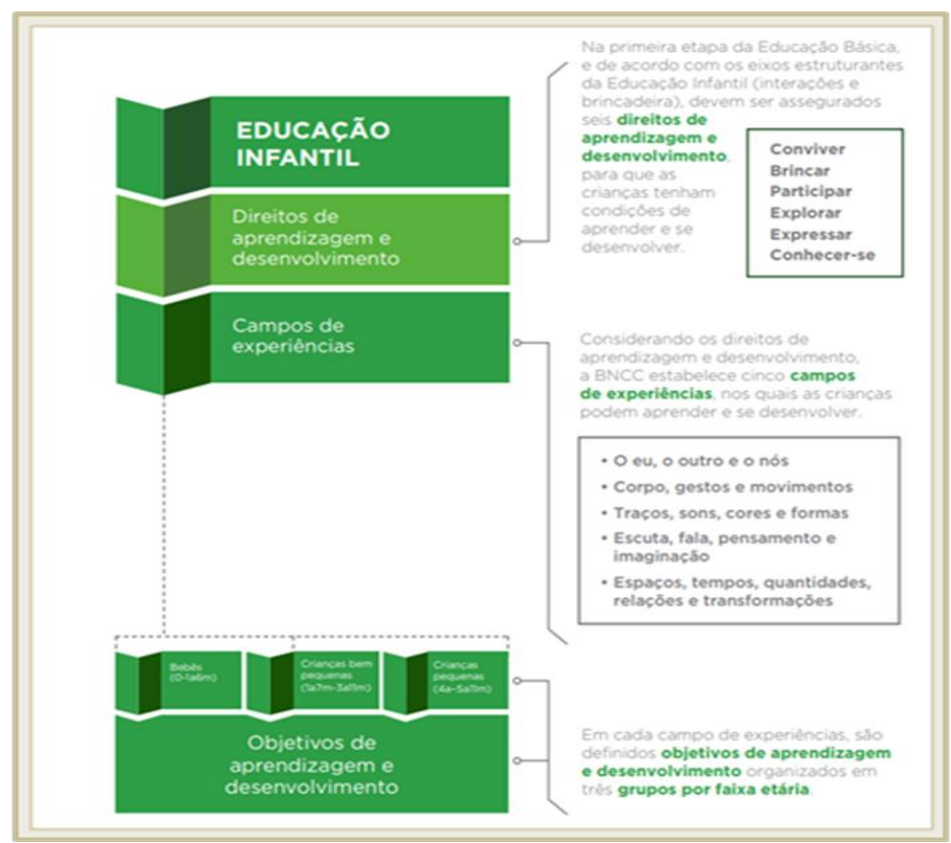

Fonte: Brasil, 2017, p.25

A organização pretende instrumentalizar a ação docente, detalhando os objetivos de aprendizagem e desenvolvimento, associados às respectivas faixas etárias (Figura 2). Deste modo, cada objetivo é identificado por um código que segue a seguinte lógica: 
Figura 2 - Objetivos para Educação Infantil expressos na BNCC, por faixa etária

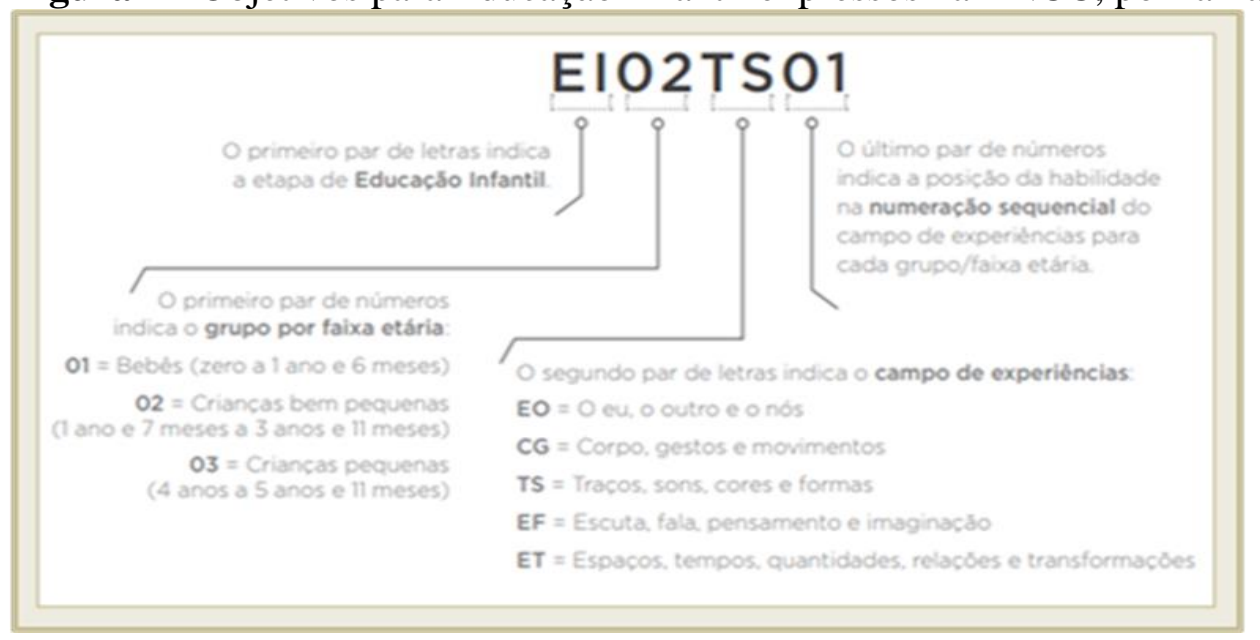

Fonte: Brasil, 2017, p. 30

Mas se a experiência não se vincula a realidade como tal, se nenhum sentido é previamente dado, nada está pronto, tudo está sempre se fazendo, como é possível reduzi-las a verificação e aplicabilidade de perspectivas tão estruturais?

Os direitos de aprendizagem apresentam-se indicando as aprendizagens essenciais e assegurando, na Educação Infantil, as condições para que as crianças aprendam e a partir daí se desenvolvam. Aliada a perspectiva de direito, os "campos de experiência" aparecem como alicerce das suas próprias interações, ou seja, de suas experiências. Uma proposição que, a primeira vista, parece apaziguar os ânimos que clamam por um currículo que atente para as especificidades da infância e assuma um currículo a partir dos campos de experiência. Quem ousaria questionar um currículo que se erige a favor do direito das crianças e de suas experiências?

A ideia da lei como registro de garantia de direitos é, geralmente, aceita e, embora a própria relação direito e lei mereçam maior atenção, vamos nos ater, aos aspectos que dizem respeito ao direito à educação e as tentativas de garantia desse direito. A problematização proposta aqui então, perpassa pela indagação a respeito da garantia de educação como direito. Se a educação é um direito humano, que sentidos de educação estão em questão?

A Figura 3 exemplifica as competências gerais propostas na BNCC e evidencia a "transformação" dos campos de experiências da educação infantil em: áreas do conhecimento, competências específicas e componentes curriculares no Ensino Fundamental, o que nos faz indagar sobre uma estruturação que, na tentativa de garantir o que é comum, infere sentidos homogeneizantes também às experiências. 
Figura 3 - Competências gerais expressas na BNCC

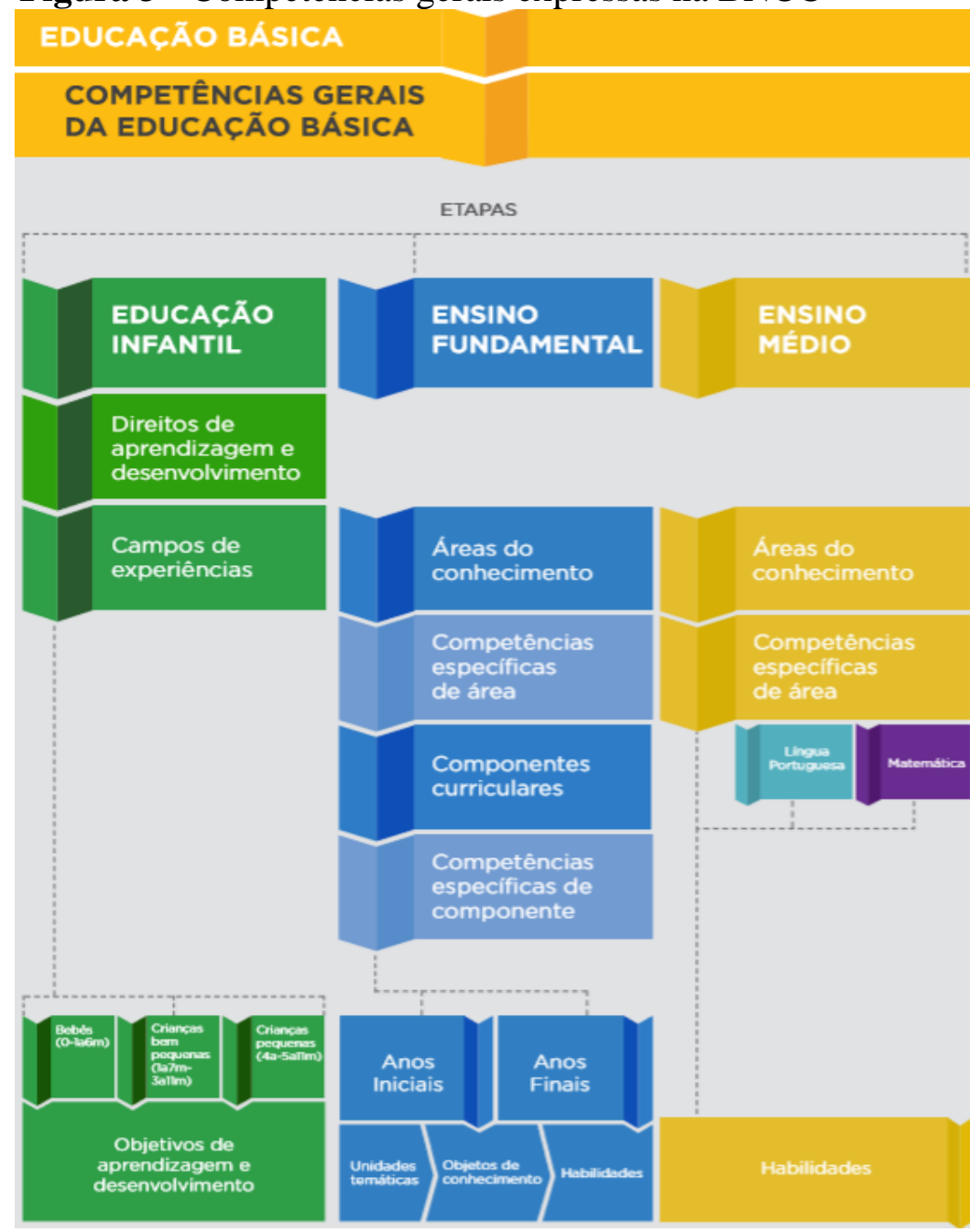

Fonte: Brasil, 2017, p.24

Ao tomar os campos de experiência como alicerce, cria-se uma forma de regulação refinada, na medida em que se toma a própria experiência como protagonista, assumindo um papel que se sobrepõe à vida das crianças. Como sugerem Abramowicz, Cruz e Moruzzi (2016) as experiências, da maneira como estão formuladas são estratégias de aprendizagem, "pois é preciso compreender que o poder já não se exerce desde fora, nem de cima, mas como que por dentro, pilotando nossa vitalidade social de cabo a rabo, ou seja, opera na própria existência da criança” (p. 58). Na BNCC, os sentidos de experiência são também evidenciados na explicitação das competências gerais, como por exemplo:

Valorizar a diversidade de saberes e vivências culturais e apropriar-se de conhecimentos e experiências que lhe possibilitem entender as relações próprias do mundo do trabalho e fazer escolhas alinhadas ao exercício da cidadania e ao seu projeto de vida, com liberdade, autonomia, consciência crítica e responsabilidade (BRASIL, 2017, p. 9, grifo nosso). 
O documento normatiza experiência como apropriação, e nesse sentido, evidencia-se a composição de forças que, associadas ao currículo, criam e fazem prevalecer algumas temáticas em detrimento de outras e as diferenças e vivências culturais que o documento preconiza, acabam por assumir as nuances de quem os classifica. Em tempos de propostas políticas associadas à utopia da escola e das relações entre todos numa perspectiva de neutralidade, incorremos no risco de organizar, sob o manto da diversidade cultural, algo que se propõe nacional e comum numa perspectiva que homogeneíza e busca unicidade. Pautada numa proposição de universalização reside o ideário de uma projeção de identidade nacional que aloca a diferença como diversidade, tal qual expresso no documento:

\begin{abstract}
A Base Nacional Comum Curricular (BNCC) é um documento de caráter normativo que define o conjunto orgânico e progressivo de aprendizagens essenciais que todos os alunos devem desenvolver ao longo das etapas e modalidades da Educação Básica, de modo a que tenham assegurados seus direitos de aprendizagem e desenvolvimento, em conformidade com o que preceitua o Plano Nacional de Educação (PNE) (BRASIL, 2017, p. 7).
\end{abstract}

Definido seu caráter de normatividade, a BNCC intenciona assegurar direitos de aprendizagem e desenvolvimento expressamente referenciados como comuns. A defesa de uma Base Nacional Comum reverbera como meio de "garantir" qualidade à educação, tal qual aponta Macedo (2014):

A defesa de uma base nacional comum para o currículo tem funcionado como uma
das muitas promessas de dar qualidade à educação para diferentes grupos da
sociedade. Ela responde a múltiplas demandas; se apresenta como capaz de garantir,
entre outros, redistribuição de renda e reconhecimento das diferenças (Moreira, 2010).
Para tanto, ela significa qualidade da educação, assim como a crise que lhe serve de
exterior constitutivo. E o faz de diferentes maneiras, tendo em vista que a
multiplicidade que constitui o social jamais pode ser estancada. (p. 1537)

É possível uma nacionalização das concepções de criança/infância? É possível uma homogeneização bem sucedida dos conhecimentos e aprendizagens, currículos e avaliações? A partir da proposta de um currículo que busca definir "aprendizagens essenciais", indagamos: a quem serve este conhecimento? Quem os define como “essenciais”? O que é essencial quando se trata de conhecimento? Questionamos, nesse sentido, a própria noção de currículo comum, pois como aponta Lopes (2018): “sujeitos diferentes não produzem nem mobilizam os mesmos saberes, não se inserem nas mesmas experiências de vida, não constroem os mesmo projetos de futuro." (p.25)

Problematizamos, deste modo, que esta tentativa de controle do "imponderável" tenta circunscrever ao currículo uma busca de conciliação que apaga as diferenças, tal qual apontam Abramowicz e Tebet (2017): 
E por que harmonizar diferenças? Em uma base comum, o que será colocado para fora? Que diferença não fará parte? O que será considerado como comum? Não há consensos possíveis sem exercício de força, saber/poder que estabeleça o que é comum[...]. A ideia subjacente à BNCC é de que há uma unidade possível na multiplicidade e que ela pode ser realizada sem a utilização da força. Nesse viés, o pensamento tem quase a função do Estado: unificar. A segunda ordem, sob a qual se assentam os argumentos aqui delineados, é a ordem das ideias, de que esta "unidade pretendida na multiplicidade" deva estar circunscrita ao currículo, metodologicamente pela via do campo de experiência. A proposta de "convergência" regida por uma normatização curricular busca afastar os conflitos e, assim, as diferenças (p. 194).

Ainda associada à defesa de homogêneo, de único, como comum, assenta-se a perspectiva de culturalização das desigualdades econômicas e sociais, como se fosse possível realizar justiça cultural em detrimento de justiça social, tudo isso pela via do currículo. "É preciso lembrar que um currículo nacional mínimo não vai melhorar a educação nem garantir desenvolvimento e melhor distribuição de renda" (Abramowicz; Cruz; Moruzzi, 2016, p. 63).

Lopes (2018) evidencia a insistência de manutenção de um vínculo imediato entre educação e desenvolvimento econômico, associado à valorização do caráter salvacionista da educação. Destaca ainda a intenção de garantias sociais de que todos serão submetidos a aprendizagens uniformes, potencializando um olhar para os docentes como incapazes de caminhar sem uma orientação curricular comum. Segundo a autora:

É possível defender que sempre há uma contextualização radical do currículo que não pode ser resolvida pela pretensão de se associar uma parte curricular comum nacional a uma parte curricular local. Isso porque não há o que se possa chamar de uma parte curricular nacional ou global pura, um contexto local puro (p. 24).

Um currículo enquanto espaço-tempo de fronteira é espaço onde culturas convivem e negociam suas existências contingencialmente, produzindo sentidos que não podem ser dados a priori. Acompanhada por Macedo (2006) nos juntamos ao coro que indaga: "Como lidar com as demandas por igualdade e diferença? Que tipo de decisões o espaço-tempo do currículo está a nos solicitar?" (p. 294).

Nos currículos escolares como espaçotempo de fronteira e, portanto, como híbridos
culturais, ou seja, como práticas ambivalentes que incluem o mesmo e o outro num
jogo em que nem a vitória nem a derrota jamais serão completas. Entendo-os como
um espaço-tempo em que estão mesclados os discursos da ciência, da nação, do
mercado, os "saberes comuns", as religiosidades e tantos outros, todos também
híbridos em suas próprias constituições. É um espaço-tempo em que os bens
simbólicos são "descolecionados", "desterritorializados" (Ibid., p. 289).

A autora fala ainda sobre a possibilidade de um currículo que, ao mesmo tempo, possa fortalecer certos grupos e potencializar resistências, permitindo que as diferenças apareçam na negociação. Referendada em Bhabha, argumenta que nenhuma diferença se mantém a despeito da dominação, do mesmo modo que nenhuma dominação tem o poder de extinguir as 
diferenças, trata-se, portanto de um espaçotempo em que as culturas presentes negociam com “a diferença do outro.” (Ibid., p. 292).

Sua discussão avança na compreensão da impossibilidade de fixação das culturas presentes no espaço-tempo do currículo e mais uma vez acompanhada por Bhabha potencializa a compreensão de alternativas no entre-lugar desses supostos lados, onde as culturas podem conviver e negociar sua existência. "O espaço-tempo do currículo, lido como uma performance cultural específica, contingente e particular, permite-nos acessar "os rastros de todos os discursos disciplinadores e instituições de saber que constituem a condição e os contextos da cultura" (Ibid., p. 229).

E como sugere Derrida (2011), a diferença reside na singularidade do acontecimento, da experiência, porque se relaciona com o outro a quem não posso programar, prever, determinar de antemão. Deste modo, pensar a Educação na perspectiva da diferença e da experiência, possibilita pensá-la sobre outras BASES, que escapem aos moldes escolarizantes da/para infância, argumentando acerca da impossibilidade de, diante da complexidade subscrita às experiências, analisar políticas curriculares com BASE nesta relação que reduz a educação ao ensino e sobre ela mantém um realismo que posiciona a educação como acontecimento calculado, previsto, definido.

Não se trata, contudo, de negar ou invalidar a existência de documentos curriculares oficiais, "essa é uma produção que se dá no atravessamento de múltiplos contextos que se interconectam e põe em disputa a produção de sentidos para a prática pedagógica." (Frangella, 2016, p.164). A autora afirma ainda que não se trata de focalizar apenas as questões locais, mas articulá-las com demandas gerais sem aniquila-las, ou seja, na constante negociação/tensão que mantém a produção como processo contínuo e inacabado.

O caminho é, portanto, pensar as articulações locais e as relações de poder que compõe a própria escola. A escola como campo de luta funda-se numa compreensão de currículo como prática cultural, fortalecendo o discurso de cultura como processo de significação e o distanciando de uma perspectiva de reprodução de uma cultura dominante, na medida em que as articulações e negociações se dão a partir de um olhar para a diferença.

Evidencia-se, portanto o quanto a institucionalização de uma Base Nacional Curricular Comum aponta para um processo educativo que pressupõe o monitoramento das práticas pedagógicas e o acompanhamento da aprendizagem e do desenvolvimento das crianças, fundamentado na “observação sistemática, pelo educador, dos efeitos e resultados de suas ações para as aprendizagens e o desenvolvimento das crianças, a fim de aperfeiçoar ou corrigir suas práticas, quando for o caso.” (Brasil, 2017, p. 35). Nessa lógica, tal qual nos sugere Lopes 
(2018), a BNCC é concebida para suprir o que falta à escola, ao docente, as práticas e nesse sentido "quanto mais se deseja afirmar o valor da BNCC, mais se significa a escola" (p. 25).

Ao reconhecer este movimento que, em certo momento detêm, ainda que provisoriamente, discursos e a existência de instrumentos como uma Base Nacional Curricular Comum para a Educação Infantil projetam-se como forma de controle, medida e padronização da aprendizagem. Neste jogo de significação do que deve ou não ser ensinado/aprendido, desconsidera-se que a institucionalização destes conhecimentos não garante uma distribuição igualitária dos mesmos, na medida em que estes não são apenas lidos, mas traduzidos e constantemente ressignificados. Vemos, no entanto, mesmo diante da impossibilidade de constituição de uma homogeneidade curricular, a insistência na manutenção de um projeto unificador sob o argumento de investimento na qualidade da educação.

Macedo (2018) ao referir-se a expressão "A base é a base", expressa na abertura da primeira versão do documento, questiona:

O que esta frase nos diz sobre a ideia de educação com que o MEC trabalha? Que a base de que se está falando - nacional curricular comum - é o mesmo que (ou contempla) a educação que pretendemos dar às nossas crianças. Não fosse este um dos sentidos possíveis, o trocadilho não se aplicaria. A leitura mais benevolente, diznos que a educação é a base para outras conquistas, seja para o país, seja para cada um de nós. Ainda que se tenha construído em torno deste segundo sentido uma certa aura positiva, há, nele, a assunção de que a educação precisa, pragmaticamente, ser útil para algo que virá. Assim, ela é marquetizada, um bem a ser trocado no mercado futuro. (p.29)

Macedo (2018) amplia a discussão, propondo-nos pensar sobre o sentido de currículo em ação (grifo nosso) mobilizado pela BNCC. Segundo a autora, na BNCC, o currículo em ação é uma releitura do currículo formal que ocorre por ocasião de sua implementação e acrescenta:

Talvez se possa defender que a releitura, ao focar no local, abriria o currículo às experiências dos sujeitos. Uma experiência, no entanto, projetada em nível municipal, escolar ou da sala de aula, não a experiência imprevisível que a própria ideia de um currículo nacional necessário torna difícil conceber. Para a BNCC, a complementaridade entre currículo prescrito e currículo em ação é da ordem da aplicação, a Base será implementada como currículo em ação. (p.30)

A defesa de um currículo como experiência não significa que não há aprendizagem e desenvolvimento. Estas, no entanto, são significadas de outra forma que não a da previsibilidade das listadas antecipadamente. Trata-se de processos de significação e diferimento que incitam produção de conhecimento. A existência de um currículo e a definição de parâmetros não podem significar engessamento de fronteiras, mas a possibilidade delas 
plasticamente se desfazerem/refazerem no fluxo da significação, na possibilidade de um currículo como acontecimento.

Como nos sugere Lopes (2018), a educação é muito mais do que ensinar conhecimentos, produzir resultados de exames, fixar e transmitir conteúdos que se preocupe com um suposto sujeito universalmente educado. "Educação se remete a cultura, aos processos de identificação imprevisíveis e incontroláveis, à constante dinâmica incomensurável entre permanência e mudança”. (p. 27)

\section{Para pensar em outros itinerários possíveis...}

A institucionalização de políticas de centralização curricular, leis de obrigatoriedade de matrícula para crianças de quatro anos de idade na pré-escola, entre outros mecanismos, nos sugere um possível resgate a uma "tradição" que se fundamenta na existência de conteúdos e de expectativas enquadradas em etapas de desenvolvimento. A garantia de direitos a uma educação pública e de qualidade que ratifique o direito de aprendizagem, se esvazia de sentido, quando, na busca pela redução das desigualdades, promove-se uma definição de currículo numa perspectiva hierárquica de conteúdos que devem ser aprendidos, definidos aprioristicamente, expurgando a diferença.

$\mathrm{O}$ argumento de que a existência de uma Base apenas "embase" o trabalho a partir da fixação de objetivos, nos faz questionar tal posicionamento, na medida em que compreendemos que esta normatividade, ainda que não estabeleça um manual de "como fazer", silencia debates sobre políticas no sentido de democratização, cedendo voz a um projeto unificador que aponta para as tendências de uniformização/centralização curricular e responsabilização de professores e gestores.

Conforme exposto por Macedo (2018), não é à toa que as competências são inicialmente apresentadas de modo mais global e logo em seguida desdobram-se em habilidades, como algo que é esperado, "não uma base de onde se parte, mas uma descrição de onde chegar" (p. 32).

É importante destacar que não nos posicionamos aqui a partir de radicalismos, ou seja, não se trata de uma posição que destitui ou nega a possibilidade de produção de documentos curriculares como propostas coletivas e que destinem-se aos sistemas de ensino, no entanto, contrárias à ideia de uma centralização curricular, a maior preocupação que nos engaja nesse debate é a perspectiva da diferença, uma vez que a política de estabelecer uma base nacional e comum para os currículos produz um único significado para o currículo. Nesse sentido, há que 
se arguir: O que cabe na base? Em um currículo comum a todos, qual o espaço possível para a experiências, para a diferença?

Embasadas na discussão curricular aqui referenciada, discutimos a existência de uma Base Nacional Comum Curricular para a Educação Infantil, inquirindo este olhar para uma infância normatizada por um documento que delimita os direitos de aprendizagem aos objetivos e conteúdos. Essa tentativa de apagamento das diferenças e das experiências singulares evidencia uma relação marcada pela verticalidade, pela hierarquização, pois a compreende numa a tentativa de contenção/negação das diferentes possibilidades de significação do currículo e da própria Educação Infantil. Trata-se de um processo, no entanto, que não pode ser contido, porque ele é próprio da linguagem.

A manutenção de um projeto fixado como o melhor para todos, um conhecimento ou uma cultura comum, universalizados de uma vez por todas como melhor para todos, pode igualmente justificar toda e qualquer intervenção política, mesmos as autoritárias, em detrimento da heterogeneidade e da negociação contextual capaz de criar a significação de currículo para múltiplos projetos possíveis. (Lopes, 2015, p. 461).

A defesa que fazemos, ao tensionar aspectos no campo da infância, se articula na aposta por melhores possibilidades educativas, entendendo que reduzir o espaço escolar somente ao "ensino", é excluir da escola sua melhor versão. O currículo como espaço-tempo de negociações provisórias e contínuas, faz-nos compreender que mesmo mediante a tentativa de fixação e fechamento, haverá sempre um currículo habitado por ambivalências. Assumir uma leitura como esta que considera a alteridade, as ambivalências e por consequência a impossibilidade de definição última, aponta para o caráter indecidível do currículo, de modo que toda opção será sempre uma decisão frente a indecidibilidade (Derrida, 2010). A escola como acontecimento faz-se na imprevisibilidade. As experiências são como um acontecimento que rompe com a lógica vigente, pois ele é da ordem da alteridade. Surge sempre pela primeira e última vez.

\section{Referências}

ASSOCIAÇÃO BRASILEIRA DE CURRÍCULO. Documento produzido pela Associação Brasileira de Currículo (ABdC) encaminhado ao CNE no contexto das Audiências públicas sobre a BNCC. 2017. Disponível em: https://www.abdcurriculo.com.br/documentos. Acesso em mar/2019.

ABRAMOWICZ, Anete; TEBET, Gabriela Guarnieri de Campos. Educação Infantil: um balanço a partir do campo das diferenças. Proposições, v.28, supl 1, 2017, p.182-203. 
ABRAMOWICZ, Anete; CRUZ, Ana Cristina J; MORUZZI, Andrea B. Alguns apontamentos: a quem interessa a base nacional comum curricular para a educação infantil? Debates em Educação, Maceió, Vol. 8, nº 16, Jul./Dez. 2016, p.46-65.

BIESTA, Gert. Para Além da Aprendizagem: Educação Democrática para o futuro humano. Belo Horizonte: Autêntica Editora, 2017.

BRASIL. Constituição da República Federativa do Brasil. Brasília. DF: Senado, 1988.

BRASIL. Lei n ${ }^{\circ}$ 11.274/06. Altera a redação dos Arts. 29, 30, 32 e 87 da Lei n ${ }^{\circ}$ 9.394, de 20 de dezembro de 1996, dispondo sobre a duração de 9 (nove) anos para o Ensino Fundamental, com matrícula obrigatória a partir dos 6 (seis) anos de idade. Diário Oficial da União, Brasília, 07 fev. 2006. p.1.

BRASIL. Resolução n ${ }^{\circ}$, de 17 de dezembro de 2009. Fixa as Diretrizes Curriculares Nacionais para a Educação Infantil. Diário Oficial da União, Brasília, 9 dez. 2009.

BRASIL. Ministério da Educação. Base Nacional Comum Curricular. Terceira versão. Disponível em: http://basenacionalcomum.mec.gov.br/images/BNCC_publicacao.pdf. Acesso em: 20 de abril de 2017.

BRASIL. Ministério da Educação. Secretaria de Educação Básica. Diretrizes Curriculares Nacionais para a Educação Infantil. Brasília: MEC/SEB, 2010.

BRASIL. Lei n. 9.394, de 20 de dezembro de 1996. Estabelece as diretrizes e bases da educação nacional. Diário Oficial da União, Brasília, 23 dez. 1996.

BRASIL. Ministério de Educação e do Desporto. Referencial curricular nacional para educação infantil. Brasília, DF: MEC, 1998.

BRASIL. Estatuto da Criança e do Adolescente, Câmera dos Deputados, Lei no 8.069, de 13 de julho de 1990. Diário Oficial da União de 16/07/1990 - ECA. Brasília, DF.

BRASIL. Plano Nacional de Educação. 2001. Disponível em http://portal.mec.gov.br/arquivos/pdf/pne.pdf.

CAMÕES, Maria Clara de Lima Santiago. O currículo como um projeto de infância: afinal o que as crianças têm a dizer? Tese (doutorado em Educação) - Programa de Pós-Graduação da UERJ, Universidade do Estado do Rio de Janeiro, 2019.

DERRIDA, Jacques. Força de Lei: o fundamento místico da autoridade. São Paulo: Editora WMF Martins Fontes, 2010. $2^{\text {a }}$ Edição.

DERRIDA, Jacques. A escritura e a diferença. São Paulo: Perspectiva, 2011.

DERRIDA, Jacques. Uma certa possibilidade impossível de dizer o acontecimento. 2012. Disponível em: http://periodicos.unb.br/index.php/cerrados/article/view/8242/6240 Acesso em 02.mar.2017. 
DIDONET, Vital. Entrevista realizada em 26/11/09. Disponível em: http://www.campanhaeducacao.org.br/?pg=Entrevistas. Acesso em: 03/12/18.

DRUMMOND, Rosalva de Cássia Rita. Do Direito à Educação aos Direitos de Aprendizagem: a escola sub judice. Tese - Doutorado em Educação doo Programa de PósGraduação da UERJ, Universidade do Estado do Rio de Janeiro, 2019.

FRANGELLA, Rita de Cássia. Por entre passagens: escola e currículo ou escolas e currículos? IN: FRANGELLA, Rita de Cássia (org.) Políticas curriculares, coordenação pedagógica e escola: desvios, passagens e negociações. Curitiba: Editora CRV, 2016.

LOPES, Alice. Apostando na produção contextual do currículo. In: AGUIAR, M.A. da S. e DOURADO, L. F. A BNCC na contramão do PNE 2014-2024: avaliação e perspectivas. Recife: ANPAE, 2018.

LOPES, Alice; CUNHA, Erika Virgílio Rodrigues da. Base Nacional Comum Curricular no Brasil: Regularidade na Dispersão. Investigación Cualitativa, 2(2), 23-35, 2017, p.23-35.

MCCOWAN, Tristan. O direito universal à educação: silêncios, riscos e possibilidades. Práxis Educativa, v.6, n1, 2011, p. 9-20.

MACEDO, Elizabeth. "A base é a base". E o currículo é o que? In: AGUIAR, M.A. da S. e DOURADO, L. F. A BNCC na contramão do PNE 2014-2024: avaliação e perspectivas. Recife: ANPAE, 2018.

MACEDO, Elizabeth. Base Nacional Curricular Comum. Revista e-Curriculum, São Paulo, v. 12 , n. 03 , out./dez. 2014 , p. $1530-1555$.

MACEDO, Elizabeth. Relações macro/micro na pesquisa em currículo. Cadernos de Pesquisa. Campinas, v.36, n.129, set./dez. 2006, p. 619-635. 